\title{
SUCCESSFUL PREGNANCY OUTCOME IN PATIENT WITH SEPTATE UTERUS WITH BAD OBSTETRIC HISTORY
}

\author{
Kavita Sujay Kabade1, Manisha Manish Laddad²
}

1 Private Consultant. Krishnamai Hospital, Ashta.

${ }^{2}$ Associate Professor, Department of Obstetrics and Gynaecology, Krishnamai Multispecialty Hospital, Karad.

\section{ABSTRACT}

\section{BACKGROUND}

Mullerian duct anomalies are the most common congenital anomalies of the reproductive system occurring in about 2 - 3 percent of women and Septate uterus is the most frequently diagnosed Mullerian anomaly. This is a case report of a 24-year-old, $4^{\text {th }}$ gravida with bad obstetric history with no previous live issue with septate uterus (uncorrected) with successful pregnancy outcome in the index pregnancy.

\section{KEYWORDS}

Septate Uterus, Mullerian Anomalies.

HOW TO CITE THIS ARTICLE: Kabade KS, Laddad MM. Successful pregnancy outcome in patient with septate uterus with bad obstetric history. J. Evolution Med. Dent. Sci. 2017;6(8):659-660, DOI: 10.14260/Jemds/2017/141

\begin{abstract}
BACKGROUND
Septate uterus is the most common structural anomaly of all Mullerian defects. It is included in class $5^{\text {th }}$ of the AFS classification of anomalies of Mullerian ducts. Fusion of the median septum of the Mullerian ducts proceeds cephalad from the Mullerian tubercle up to the junction of future round ligaments; shortly thereafter, the septum between the ducts is resorbed. Congenital defects can occur because of failure of lateral fusion. If the two horns of the partially fused uterus are recognisable, the uterus is diagnosed as a bicornuate uterus. However, if the external configuration of the uterus is relatively normal and malfusion is represented only by a septum within the uterus, it can be referred to as a septate uterus.
\end{abstract}

A cornual pregnancy results from nidation in one horn of a bicornuate uterus, a unicornuate uterus or in lateral half of a septate uterus, and is therefore not strictly an ectopic pregnancy.[1]

\section{CASE REPORT}

My patient, 24 years, $4^{\text {th }}$ gravida who conceived the index pregnancy spontaneously and came at 8 weeks for her first antenatal care. Past Obstetric History: G1, G2 - Both preterm vaginal home deliveries. Both babies died within $24-48$ hours of birth at home.

G3 - 12 - 14 weeks' spontaneous abortion at home.

G4 - Present pregnancy.

- Ultrasonography done in first trimester was s/o single live intrauterine foetus of AGA of 8.2 weeks (+/- 10 days) in right cornua of?? Bicornuate?? Septate uterus.

- She was started on injectable progesterone and other necessary medications for the same and rest advised. Cervical encirclage was done in early second trimester. After completion of 7 th month, prophylactic steroid therapy was given.

Financial or Other, Competing Interest: None.

Submission 01-12-2016, Peer Review 14-01-2017,

Acceptance 20-01-2017, Published 25-01-2017.

Corresponding Author:

Dr. Kavita Sujay Kabade,

Krishnamai Multi-Speciality Hospital,

Ashta, Dudhgaon Road, Walwa, Sangli.

E-mail: drkavita2510@gmail.com

DOI: $10.14260 /$ jemds $/ 2017 / 141$

(c) $(1) \subseteq$
At 31 weeks of pregnancy, she presented with acute abruptio placenta, which was managed conservatively. After 72 hours, an obstetric USG with colour Doppler was done.

\section{Findings}

A single live intrauterine pregnancy of gestational age 31.4 (+/- 2 weeks) with reduced amniotic fluid (AFI-7 cm) with no evidence of retroplacental clot, transverse lie, cord around neck and no signs of placental insufficiency.

Tb. Sildenafil twice daily, weekly alamine infusion, $\mathrm{Tb}$. Isoxsuprine $40 \mathrm{mg}$ Retard BD and L-Arginine 3 gm sachet OD was started and weekly assessment was done.

At 34 weeks, she came in preterm labour. As the lie was transverse and steroid therapy had already been administered, so was taken up for emergency caesarean section.

A live male infant weighing 1900 gms was delivered by breech. Baby cried immediately after birth and required no NICU care (as per attending paediatrician) and was handed over to relatives with explanation of all necessary precautions I/V/O preterm-prematurity. After placental delivery, a midline uterine septum was seen extending to the level of lower segment uterine.

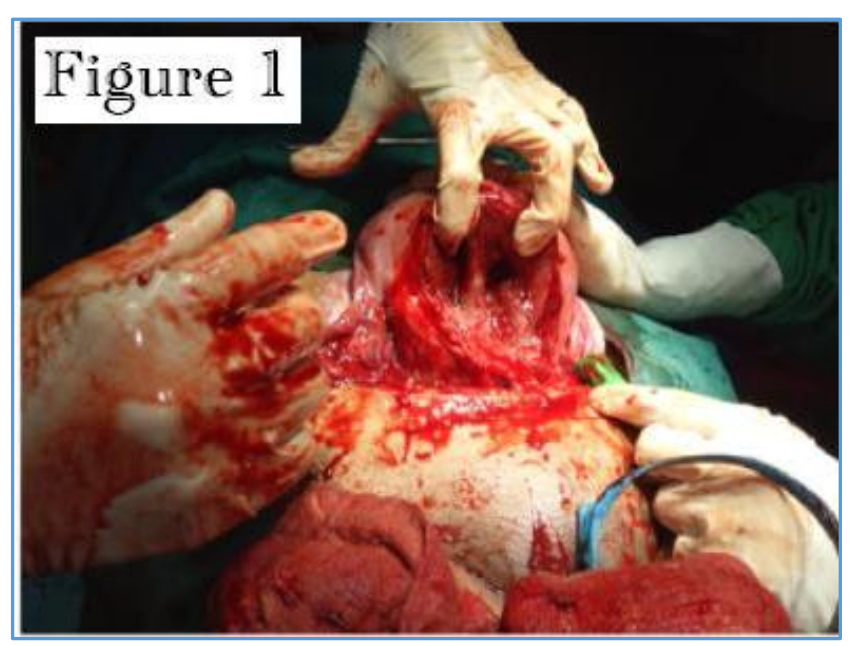

Figure 1. Incision 


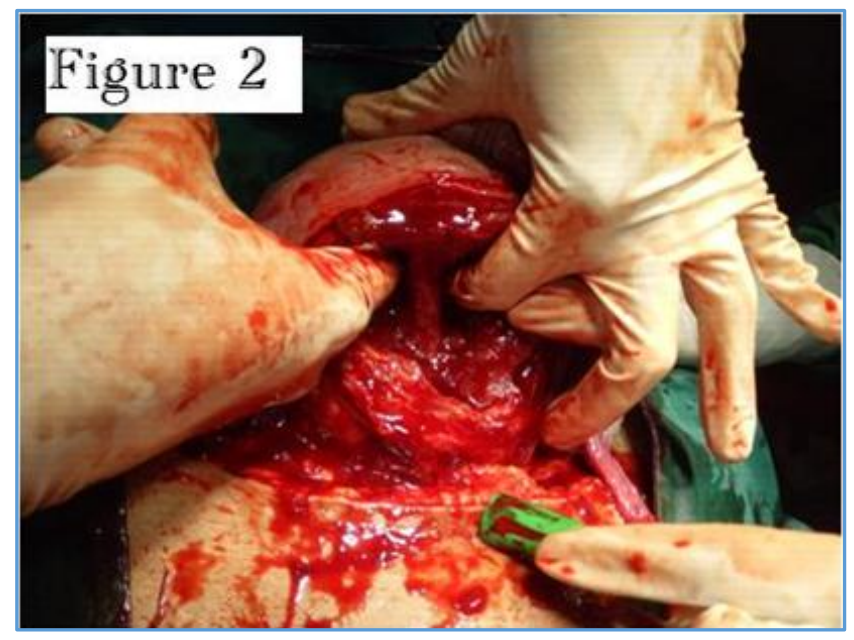

Figure 2. Dividing the Cavity into 2 Halves

In this case we did not contemplate removing the septum, because the caesarean section was an emergency intrapartum one with likelihood of genital sepsis that may complicate healing. After abdominal closure and sterile dressing of the wound, cervical encirclage stitch was removed taking all necessary aseptic precautions.

\section{DISCUSSION}

A uterine septum is a form of a congenital malformation where the uterine cavity is partitioned by a longitudinal septum. Mainly, the serosal surface of the uterus has a normal typical shape. The wedge-like partition may involve only the superior part of the cavity resulting in an incomplete septum or a subseptate uterus or less frequently the total length of the cavity (complete septum) and the cervix resulting in a double cervix. A subseptate variety was found in this patient. The septation may also continue caudally into the vagina resulting in a double vagina.[2]
The structurally anomalous uterus has long been recognised as a case of obstetric complication. Congenital malformations may be associated with recurrent pregnancy loss, preterm labour, abnormal foetal presentation and infertility.[3] The patient did not have infertility as all 4 conceptions were spontaneous, but experienced all other complications like preterm labour, recurrent pregnancy loss and abnormal foetal presentation (Transverse lie in this case).

If this patient had been diagnosed before and had undergone hysteroscopic septoplasty before conception, then maybe she had carried the pregnancy to term thus decreasing the perinatal and foetal morbidity. [4] But unfortunately as she came after conception, there was no other option except continuation and taking the necessary precautions as was done in this case. Most satisfying part of managing such case is when the mother with her baby is discharged in good condition. Good Antenatal care and management can give us successful outcome in uterine anomalies with pregnancy in rural and peripheral hospital setup.

\section{REFERENCES}

[1] Chandra M, Pathak V. Pregnancy in non-communicating half of septate uterus. J Obstet Gynecol India 2012;62(Suppl 1):31-2.

[2] Heinonen PK. Complete septate uterus with longitudinal vaginal septum. Fertilitly Sterility 2006;85(3):700-5.

[3] Raga F, Bauset C, Remohi J, et al. Reproductive impact of congenital Mullerian anomalies. Human Reproduction 1997;12(10):2277-81.

[4] Adesiyun AG, Avidime S, Umar H, et al. Term pregnancy in a patient with septate uterus: incidental finding at Caesarean section. Case reports in clinical Medicine 2014;3(3):114-7. 